\title{
ALGUNAS PUNTUALIZACIONES EN TORNO A LA FISIOCRACIA EN LA ILUSTRACIÓN TARDÍA ESPAÑOLA
}

\author{
JESÚS ASTIGARRAGA Y JAVIER USOZ ${ }^{a}$
}

En 1797 el ilustrado extremeño J. Álvarez Guerra inició la traducción del Cours complet d'agriculture del agrónomo francés Rozier. La traducción iba precedida de un Discurso que ha sido estudiado en un artículo publicado en un número reciente de esta Revista (Astigarraga-Usoz 2007a). En él se sostiene su singularidad en la España de su tiempo, debido a su afiliación doctrinal fisiócrata, y su significación como alternativa al Informe de Ley Agraria de Jovellanos. A continuación, los autores de dicho artículo respondemos a la réplica al mismo del profesor V. Llombart, a quien agradecemos sus comentarios. Éstos no añaden ninguna información adicional a nuestro artículo, sino que reconsideran críticamente nuestras conclusiones respecto a las cuatro siguientes cuestiones: el Informe de Ley Agraria es superior al Discurso; éste es una obra menor, no es fisiócrata y, finalmente, no fue una alternativa al Informe.

Sobre la primera cuestión bastaría con afirmar que nuestro artículo alude al Informe como «obra cumbre» de la Ilustración económica española. Incluso analizamos detalladamente que la iniciativa de Álvarez Guerra de traducir a Rozier fue inducida por el Informe; en este sentido, aportamos información sobre la escasamente reconocida incidencia de esta obra en el ámbito de la popularización de los conocimientos agrarios (pp. 430-433).

Entrando en lo doctrinal, el período de la Ilustración tardía española ha sido menos estudiado que el comprendido entre 1760 y 1790. Prueba de ello es que los diferentes trabajos que han mencionado la traducción de Rozier no han reparado en su Discurso ${ }^{1}$. Al mismo tiempo, Álvarez Guerra era un autor desconocido en la Historia del pensamiento económico, aunque no

a Universidad de Zaragoza. Departamento de Estructura e Historia Económica y Economía Pública, Facultad de Derecho, c/ Pedro Cerbuna, 12, 5000009 Zaragoza, astigarr@unizar.es, jusoz@unizar.es.

1 Tampoco lo hace el propio Llombart (2004: 64). 
entre los historiadores económicos ${ }^{2}$. Roto este silencio parcial con nuestro análisis del Discurso, nos ha resultado evidente su afiliación fisiocrática, por lo que, con fidelidad a nuestra investigación original, es posible rebatir las objeciones de Llombart.

Empezamos considerando que el Discurso de Álvarez Guerra no es un tratado de Economía Política. La crítica de Llombart respecto a su falta de profundidad ha de supeditarse a la circunstancia de que se trata de la introducción a una traducción, siendo lógico que predomine la síntesis sobre la explicación pormenorizada y el talante divulgativo sobre el analítico. A la vez, el Discurso no es una excepción al hecho de que los traductores europeos introdujeran ideas propias en las ediciones que resultaban de su trabajo. Llombart considera que esa labor complementaria debía de haberse canalizado a través de las notas al texto. Sin embargo, en la Ilustración española existen ediciones que incorporan ideas del traductor en formas diversas: introducción (Le Maur); notas a pie de página (Alonso Ortiz); ambas cosas (Villava); refutaciones capítulo a capítulo (Rey); incluso existe alguna obra completa realizada al hilo de una traducción (Anzano). Álvarez Guerra escogió la vía del prólogo y no es un dato marginal que su Discurso sea una de las introducciones más extensas de la Ilustración económica española. Tuvo un sentido político: este tipo de escritos no eran banales ejercicios de erudición, cuando debían pasar censuras que ponían en riesgo los derechos del traductor. Por todo ello, las traducciones constituyen un elemento central en el análisis de la circulación internacional de las ideas económicas, tal y como aprendimos de E. Lluch. En concreto, aportaciones como la de Álvarez Guerra justifican un análisis detallado, máxime al fundamentarse en la fisiocracia, cuya circulación en el siglo XVIII español se viene considerando marginal.

Llombart no acaba de precisar la doctrina esencial expuesta en el Discurso. Emplea calificativos como «fisiócrata de ocasión», «fragmentariamente fisiócrata» y agrarista «parcialmente liberal». En el fondo, se trata de responder a la ardua cuestión de cuándo un texto que contiene ideas de una fuente determinada puede ser identificado doctrinalmente con ella. En nuestro artículo ya se advertían carencias en el escrito de Álvarez Guerra respecto a la matriz fisiócrata. Así, no alude «en ningún momento al Tableau Économique, ni a la clasificación tripartita fisiócrata de clases productivas, estériles y de los propietarios», ni a la "grande culture y, quizás, al bon prix» (pp. 438 y 447). Llombart considera que falta también la teoría de los precios, la crítica al mercantilismo y a los monopolios industriales y comerciales, así como el concepto de renta de la tierra, omisiones que, por un lado, no agotan las de entidad teórica que podrían ser mencionadas y

2 A pesar de su influyente trayectoria política y de que su dilatada obra económica y agronómica le hace merecedor de un estudio en profundidad, tal y como el propio Llombart reconoce. 
que, por otro, no están tan claras. Álvarez Guerra condena las políticas británicas del comercio de granos y sostiene que la competencia es el único antídoto para evitar las concentraciones por el lado de la oferta y los monopolios, en concreto, los propios del comercio de granos. Asimismo, aunque no explique con detalle el sistema de precios, lo cual queda fuera del carácter de su Discurso, en él queda bien reflejada la idea de que la competencia es el mejor sistema para alcanzar un precio estable y «medio» y eliminar los beneficios extraordinarios. En todo caso, es indiscutible que Álvarez Guerra no demostró tener un conocimiento absoluto de la fisiocracia. Sin embargo, este criterio invalidaría numerosas filiaciones doctrinales que se han realizado de los economistas españoles de la Ilustración: ¿pasaría ese filtro, por ejemplo, el resumen considerado smithiano de Alcalá Galiano de los cinco volúmenes de la Wealth of Nations, realizado en un espacio semejante al del Discurso de Álvarez Guerra?

En el cuadro siguiente resumimos algunas de las ideas principales del Discurso:

\section{Tesis Económicas}

1. Productividad única de la agricultura

2. «Esterilidad» de la manufactura y el comercio

3. «Esterilidad» del dinero

4. Avances

5. Producto neto

6. El producto neto depende de los avances

7. El producto neto debe incluir el "premio del capital» (tasa de beneficio.)

8. "Capitalista»: agente económico que percibe la tasa de beneficio

9. Tasa de beneficio en la agricultura mayor que en la manufactura

10. Importancia de la capitalización de la agricultura

11. Relación población/subsistencias

12. Ajuste automático de la población/subsistencias sin intervención pública

13. Patrón comercial basado en la agricultura nacional

14. Intercambio comercial de frutos o materias primas por manufacturas

15. Todas las clases sociales dependen de la clase agrícola

16. Libre interés, principal incentivo de los agentes económicos

17. Efectos socioeconómicos benéficos de la plena competencia

Políticas Económicas

18. Desamortización plena de la propiedad de la tierra

19. Individualismo agrario

20. Libertad de precios

21. Libertad de arriendos

22. No a los pósitos públicos

23. Comercio basado en comerciantes privados

24. Libre comercio interior

25. Libre comercio exterior

26. Precio «medio» entre la agricultura y la manufactura 

27. Intensificación del cultivo
28. Instrucción del propietario
29. Popularización de los conocimientos agrícolas
30. Honores a agricultores distinguidos

Estructura del Sector Público

31. Impôt unique sobre el producto neto

32. Rechazo a los impuestos sobre el consumo y las manufacturas

33. Otros principios tributarios: certidumbre, no recaudadores, visibilidad

34. Reducción del sector público: marco constitucional y obras públicas

Tesis Jurídico-Políticas

35. Contrato social origen del poder político

36. Orden natural: «libertad, propiedad y comodidad»

37. Principio de seguridad jurídica

38. Definición clara de los derechos de propiedad personal, mobiliaria y de bienes raíces

39. Despotismo legal

40. Principios legales «justos, sencillos e invariables»

41. Pocos principios legales y derivados de la «naturaleza y la razón»

Todas las ideas expuestas son fisiócratas, salvo la más discutible referida al precio «medio». Ello no quiere decir que lo sean en exclusividad: las hay compartidas con autores que contribuyeron a la eclosión fisiócrata, como Cantillon (los números 11, 12, 15, etc.); con las corrientes del agrarismo liberal de los Herbert o el Mirabeau pre-fisiócrata (19, 20, 21, 24, etc.); incluso, hay ideas compartidas con adversarios de la fisiocracia como Forbonnais, Necker o Galiani (19, 24, etc.), o críticos con ella, como Smith $(19,24$, etc.). Sin embargo, hay contenidos que son genuinamente fisiócratas. Así, Álvarez Guerra emplea muy significativamente conceptos como avances, "producto neto», "tasa de beneficio» o "capitalista»; alude a la productividad exclusiva de la agricultura; y propone políticas económicas como el impôt unique, el libre comercio exterior de granos, la defensa a ultranza de la competencia y otras de indiscutible naturaleza fisiócrata. La única duda razonable es la aceptación del «bon prix». El extremeño parece inclinarse por un precio «medio» que concilie el desarrollo de la agricultura y la manufactura (26). Ahora bien, incluso este elemento es discutible, dado que eminentes economistas post-fisiócratas, como Condillac, utilizaron el análisis fisiócrata del sistema de precios para rechazar el bon prix. Por tanto, el Discurso de Álvarez Guerra armoniza plenamente con la fisiocracia.

Llombart plantea en su réplica sendas «dobles columnas» que muestran que diversos extractos del Discurso han sido extraídos de los cuatro volúmenes sobre Économie Politique et Diplomatique de la Encyclopedie Méthodique. Pero esto ya se advierte rotundamente en nuestro artículo, 
donde se indica que es «claro que en su elaboración [Álvarez Guerra] utilizó intensivamente los volúmenes» mencionados (p. 448) ${ }^{3}$. De hecho, incluso identificamos allí las voces «agricole» $\mathrm{y}$ «chine», elaboradas por el fisiócrata Grivel ${ }^{4}$, para sostener con detalle que se ha hallado una "gran similitud» entre su contenido y el Discurso de Álvarez Guerra (nota 37$)^{5}$. Lo cierto es que los textos plagiados de la Encyclopedie pueden ir más allá. Teniendo presente el problema político que en España había despertado esta obra, es muy probable que Álvarez Guerra no la mencionara por prudencia $^{6}$. No obstante, es más significativo que se inspire en las voces fisiócratas de la Encyclopédie, contenidas en sus dos primeros volúmenes, por cuanto indica que su elección doctrinal era intencionada. Como señala nuestro artículo, esa obra alfabética fue doctrinalmente plural: también contenía abundantes ideas smithianas, explicadas en sus dos últimos volúmenes por J. N. Demeunier, a las que el Discurso no es sensible. En consecuencia, si Álvarez Guerra presenta ideas y políticas genuinamente fisiócratas, y las que no lo son en su forma más característica son plenamente compatibles con los économistes, a excepción, quizás, del bon prix, no parece apropiado calificarlo de fisiócrata "ocasional», "fragmentario»y, menos aún, de mero «agrarista», escatimándole el calificativo de «liberal», cuando, en cambio, se aplica a un programa más moderado como el de Jovellanos. Desde luego, nuestra interpretación se halla mucho más próxima a otro estudio de Llombart en el que casi parece dispuesto a aceptar el calificaivo de fisiócrata para Campomanes, con unos requisitos menos exigentes que los que cumple la obra de la que tratamos ${ }^{7}$.

Teniendo en cuenta el ambiente político compartido, al que después aludiremos, es inevitable poner en relación doctrinal el Discurso y el Informe.

${ }^{3}$ Lo cual es bastante más que la «referencia a la posible utilización» de dicha obra que nos atribuye Llombart.

${ }^{4}$ Llombart no hace justicia con G. Grivel. Éste no sólo fue un novelista afamado, que utilizó sus novelas para difundir los principios del orden natural fisiócrata, sino un fisiócrata tardío de notable relevancia, autor de diversas obras sobre educación y de dos textos político-económicos: Mélanges de philosophie et d'économie politique (1789) y Principes de politique (1790). El primero reunía una parte de sus cincuenta y siete extensos artículos para l'Encyclopédie que le habían sido encargados por Baudeau.

${ }^{5}$ La «doble columna» de Llombart se basa precisamente en esas dos voces, sin apenas concretar más sobre las fuentes, indicando ambiguamente que «parece existir también alguna similitud con los cuatro primeros tomos de la sección Agricultura de la Encyclopedie Méthodique, en particular, el extenso «Premier Discours» del abate Tessier».

${ }^{6}$ Por otra parte, no deja de ser llamativo que después de ratificar los plagios de Grivel, Llombart no interprete de manera diferente las citas a Jovellanos en el Discurso. En una obra que iba a ser presentada a la Sociedad Matritense, dos años después de publicado el Informe, tales citas eran casi obligadas, pero pertenecen a cuestiones no vertebrales en la argumentación del ilustrado extremeño.

7 «Como el resto de economistas españoles contemporáneos suyos, Campomanes no fue un fisiócrata, pues no aceptó el sistema teórico y político de la «secta» (es curioso que ésta sea la única razón que encuentro para negarle la condición de «economista»), véase Llombart (2000a: 227-231). 
Decir que el primero es una alternativa al segundo ${ }^{8}$ no desmiente que ambos textos compartieran numerosas reflexiones y que se encontraran en el mismo frente, en favor de las ideas ilustradas. Una alternativa no presupone una discrepancia absoluta. La propia Ilustración se explica como portadora de un sustrato común a partir del cual se configuran múltiples alternativas. El Discurso puede ser considerado una alternativa al Informe porque un nutrido y significante conjunto de ideas del primero no se reflejan en el segundo (vid. cuadro: 1, 2, 4, 5, 6, 7, 8, 15, 18, 22, 25, 31, 32, 34, 36, 39,40 y 41 ), y en la misma medida en que calificamos de esa manera, por ejemplo, a los economistas del grupo de Gournay frente a los fisiócratas, a Turgot frente a Necker, a Smith frente a Steuart, o al agrarismo frente al industrialismo. Así, según exponemos en nuestro artículo y olvida Llombart en su réplica, Jovellanos conocía los volúmenes de la Encyclopédie utilizados por Álvarez Guerra, de los que había sido censor, pero parece que no se hizo eco de sus voces fisiocráticas, si bien es preciso seguir trabajando en las todavía no bien conocidas fuentes del Informe.

Por otra parte, sorprende que Llombart menosprecie la Encyclopédie como canal divulgador de ideas económicas, ya que cada vez son más los datos que informan de su poderoso influjo en España ${ }^{9}$. Es llamativo que minusvalore esa vía de penetración por no ser «una obra fisiócrata original», sino de "de segunda mano», cuando en España fue muy importante el uso de vías interpuestas en la recepción de autores de primera fila, como lo ejemplifica el enorme influjo del sintético compendio que Condorcet publicó en 1792 de la obra de Smith. En cuanto a la fisiocracia, ya se ha estudiado la importancia de textos menores, parcialmente fisiócratas o «de segunda fila» en la circulación internacional de sus contenidos ${ }^{10}$. Además, no se puede infravalorar las enciclopedias, especialmente en el contexto del siglo XVIII: por un lado, fueron enormemente difundidas, como fue el caso de la propia traducción de Álvarez Guerra; por otro, las elaboraron algunos de los ilustrados y economistas más distinguidos de su tiempo y supusieron una empresa cultural con una influencia renovadora extraordinaria (Astigarraga-Zabalza 2006).

El Discurso de Álvarez Guerra muestra que el Informe de Jovellanos no cerró las reflexiones en torno al Expediente de Ley Agraria, sino que las incitó y ayudó a prolongarlas en el tiempo. Desde este prisma, la contribución del extremeño cubre parcialmente un vacío, ya que no había una contribución tan particularmente fisiocrática durante las tres décadas transcurridas

${ }^{8}$ En nuestro artículo nunca se habla de «réplica», expresión utilizada provisionalmente en una prepublicación destinada a la discusión académica (Astigarraga-Zabalza, 2006).

9 Pueden verse, Barrenechea (1984), Astigarraga (2003: 208-223) y (2005), y AstigarragaUsoz (2007b).

${ }^{10}$ En esta categoría cabría clasificar al suizo Schmid d'Avenstein o al napolitano Filangieri. Ese juicio puede extenderse también a la realidad italiana y, seguramente, a otros países europeos relativamente periféricos. Vid. Astigarraga (2005). 
desde que se activó ese Expediente. En general, no se conoce en el siglo XVIII español una memoria económica tan característicamente fisiócrata como el Discurso. Campomanes, Olavide, Arriquíbar o Ramos conocieron bien a los fisiócratas, sin serlo. Respecto a la generación posterior, a diferencia de Cabarrús, Álvarez Guerra era partidario del libre comercio exterior y del impôt unique; a diferencia de Foronda, aceptaba la «esterilidad» de la industria; y a diferencia de Salas, no creía necesario diferenciar las estrategias de desarrollo entre los países agrícolas y los manufactureros. A la luz de estas singularidades, se trata de una de las síntesis fisiócratas más características del siglo XVIII español; por ello, y a pesar de su carácter más divulgador que analítico, no fue un escrito «menor».

La Ilustración económica se nutrió de corrientes diversas. Como ha mostrado Llombart, la obra de Jovellanos supuso una culminación del reformismo ilustrado oficial. Ahora bien, aquella obra no reflejaba todas las sensibilidades reformadoras presentes en el tramo final del siglo. Hubo alternativas partidarias de reformas más moderadas (Anzano) ${ }^{11}$, como las hubo en una corriente más audaz (Foronda, Cabarrús, Salas o el mismo Álvarez Guerra) ${ }^{12}$. Esta corriente emergió alrededor del debate constitucional iniciado en España en torno a 1780. Por ello les resultaba útil la fisiocracia, en cuyo análisis del orden natural las facetas política y económica aparecían indisolublemente unidas. Ello contribuye a explicar el reverdecer de la fisiocracia en el tramo final del siglo XVIII español, en manos de una Ilustración tardía y radical, a través de textos mucho más influyentes en su tiempo de lo que la Historia del pensamiento económico les ha venido reconociendo (Schmid d'Avenstein, Filangieri, la Encyclopédie, etc.). En este sentido, el concepto de «despotismo legal» no hubo de resultar retrógrado a los reformistas contemporáneos de Álvarez Guerra. Ni un orden natural que implicaba reformas constitucionales y económicas de un calado superior a las del Informe. No se debe olvidar que fue precisamente Grivel, inspirador de Álvarez Guerra, el fisócrata tardío que compatibilizó el orden natural y el contrato social, permitiendo una lectura liberal y antidespótica del orden natural fisiócrata (Barrenechea 1984: 133-134).

Por último, una mención a las circunstancias históricas en las que Álvarez Guerra elaboró su escrito. En nuestro artículo se señala que el extremeño era discípulo de Salas en la Universidad de Salamanca y que había testificado a su favor en el juicio al que le sometió la Inquisición y que acabó, en 1795, en una dura condena que privó al maestro de libertad, propiedades y cátedra. Salas alimentó un núcleo de pensamiento político y económico radical que tuvo uno de sus referentes indiscutibles en las ideas fisió-

${ }^{11}$ En Usoz (2008) se adelantan algunas tesis que desarrollamos en un artículo en vías de publicación.

12 Según Llombart (2000b: 121), el ideario de Cabarrús estaba «muy alejado del posibilismo y gradualismo reformista de Jovellanos»; por eso extraña que se resista a ampliar esa sensibilidad reformadora más radical a Álvarez Guerra. 
cratas. Sin tener que apoyarnos en trabajos venideros ${ }^{13}$, ya hemos demostrado que se le acusó, en particular, de haber traducido al fisiócrata Schmid d'Avenstein. Y hay pruebas incontestables de que la Encyclopédie circuló intensamente en los círculos salmantinos ${ }^{14}$. Todo ello quiere decir que esa corriente radical estaba teniendo problemas para trasladar a la esfera pública su programa, como los tuvo Cabarrús para publicar sus Cartas. Álvarez Guerra comenzó la elaboración de su traducción en 1796, encarcelado su maestro. De ahí que ésta hubo de constituir también una contribución con alta significación política, en unas circunstancias muy difíciles para quien había ejercido como testigo a favor de un condenado por delitos graves. Se explica, pues, la simplificación y la omisión de algunas fuentes del Discurso. Ahora bien, frente a lo que afirma Llombart, su contenido no se «desvaneció después de ser escrito y publicado». La lectura atenta de una muy exitosa memoria a favor de la desamortización publicada por Álvarez Guerra en 1813 pone de relieve que su reformismo radical no había remitido. Aunque se presentara bajo una forma no estrictamente fisiocrática, hay un hilo conductor entre ella y el Discurso de 1797. En suma, la fisiocracia fue una de las raíces del liberalismo económico y político español, aunque, en el preciso contexto de finales del siglo XVIII, fuera inspiradora tan sólo de una de las corrientes económicas de la Ilustración española que se hicieron visibles entonces y que acompañaron la publicación del Informe de Jovellanos.

\section{BIBLIOGRAFÍA}

AstigarRaga, J. (2003): Los ilustrados vascos. Barcelona: Crítica.

- (2005): "La Fisiocracia en España: los Principes de la législation universelle (1776) de G. L. Schmid d'Avenstein». Historia Agraria 37.

- (2008): «Iusnaturalismo moderno de la mano de la Economía Política: las Apuntaciones al Genovesi de R. de Salas». Historia Constitucional, núm. 9.

Astigarraga, J., y Zabalza, J. (2006): La Economía en los diccionarios y las enciclopedias del siglo XVIII en España. Documento de Trabajo de la AEHE, DT-0607.

AstigarRaga, J., y Usoz, J. (2007a): "Una alternativa fisiócrata al Informe de Ley Agraria de Jovellanos». Revista de Historia Económica, XXV-3.

- (2007b): «Political Economy and Republicanism in late Eighteenth Century Spain: R. de Salas' Apuntaciones to Genovesi's Lezioni di commercio», en P. F. Asso y L. Fiorito (eds.), Economics and Institutions. Milan: Franco Agneli.

BARRENECHEA, J. M. (1984): Valentín de Foronda, reformador y economista ilustrado. Vitoria: Diputación Foral de Álava.

Llombart, V. (2000a): "Campomanes, el economista de Carlos III», en E. Fuentes Quintana (dir.), Economía y economistas españoles. La Ilustración. Barcelona: Galaxia Gutenberg-Círculo de Lectores. (2008)

${ }^{13}$ En una primera entrega, véase el análisis iusnaturalista radical de Salas en Astigarraga

14 En el A.H.N., Consejos, leg. 11.925, se hallan manuscritas diversas voces de esa obra francesa, cuya autoría se atribuye a Salas. 
- (2000b): «Jovellanos, economista de la Ilustración tardía». Estudio Preliminar a G. M. Jovellanos, Escritos económicos. Madrid: Real Academia de Ciencias Morales y Políticas.

- (2004): «Traducciones españolas de Economía Política 1700-1812): catálogo bibliográfico y una nueva perspectiva». Cromohs 9 .

Usoz, J. (2008): "La política ilustrada y el libre comercio de granos: las "Reflexiones económico-políticas" (1768) de Tomás Anzano». Historia Agraria 44. 
